\title{
Circular Patch Antenna with C-shape Slot for UWB Application
}

\author{
Sheetal kamboj \\ M.Tech Scholar \\ BMSCE, Muktsar
}

\author{
Amit kumar \\ Assist. Prof. ECE Deptt \\ BMSCE, Muktsar
}

\begin{abstract}
A novel compact and ultrawide-band (UWB) antenna is presented in this paper. A novel CPW-fed monopole circular patch UWB antenna with c-shape slot is proposed in this article. IE3D simulator is used to analyze the proposed antenna in the design process. The proposed antenna has an extremely wide frequency band range, the impedance bandwidth of which is measured as 4.2 to $10.5 \mathrm{GHz}$ for return loss <_10 dB. Simulated and measured results are presented for the proposed antenna.
\end{abstract}

\section{Keywords}

CPW-fed, ultra wideband (UWB)

\section{INTRODUCTION}

Ultra-wideband (UWB) technology is one of the most promising solutions for future communication systems due to its high speed data rate and excellent immunity to multi-path interference. As the key components of UWB system, the feasible UWB antenna design face some challenges including the Ultra wide band performance of the impedance matching and radiation stability, the compact antenna size, and the low manufacturing cost for consumer electronics application. Because the CPW fed planar slot antennas have the advantages of wide bandwidth, low cost and easy to integration with radio frequency front end circuitry $[1,2$, and $3]$.

In general planar slot antennas two parameters affect the impedance bandwidth of the antenna, the slot width and feed structure $[4,5]$. The wider slot gives more bandwidth and the feed structure gives the good impedance matching [6,7]. The CPW feed line with various possible patch shapes. Such as T cross, Circular Slot, arc shape and square is used for wide bandwidth $[8,9]$.

In this article, a CPW-fed circular patch with c-shape slot monopole UWB antenna is proposed. The proposed antenna not only has a simple structure but also has an extremely wide frequency band range, the bandwidth of which is measured as 4.2 to $10.5 \mathrm{GHz}$ for return loss $<10 \mathrm{~dB}$. The detailed design and experimental result of the proposed antenna are presented and discussed.

\section{ANTENNA DESIGN}

Figure 1 illustrates the proposed circular patch antenna with cshape slot for UWB applications. This antenna was printed on FR4 substrate with thickness of $1.6 \mathrm{~mm}$ and relative permittivity of 4.4. The configuration of the proposed antenna is shown in figure 1 . The dimension of the antenna is $\mathrm{L} \mathrm{X} \mathrm{W}$ $=33 \mathrm{~mm} \times 24 \mathrm{~mm}$. As shown in the figure 1, the antenna consists of circular shape patch consisting c-shape slot in it. The antenna is constructed with the above described patch and fed by Coplanar Waveguide Feed (CPW) feeding. The ground size of the proposed antenna is $12.4 \mathrm{~mm} \times 9.4 \mathrm{~mm}$. The ground plane is symmetrical at the base line of the feeding strip line. To obtain the optimal parameters of the proposed antenna for UWB application, IE3D, full-wave commercial EM software that can simulate a finite substrate and a finite ground structure, is used. Thus, the proposed antenna design can provide a wide bandwidth while retaining stable performance via the optimized geometrical parameters. The parameters of proposed antenna are shown in Table 1 . The rectangular strip feed line has dimensions of $13 \mathrm{~m} \times 3.5 \mathrm{~mm}$. The distance between patch and ground is $0.6 \mathrm{~mm}$ and between feed and ground is $8.7 \mathrm{~mm}$.

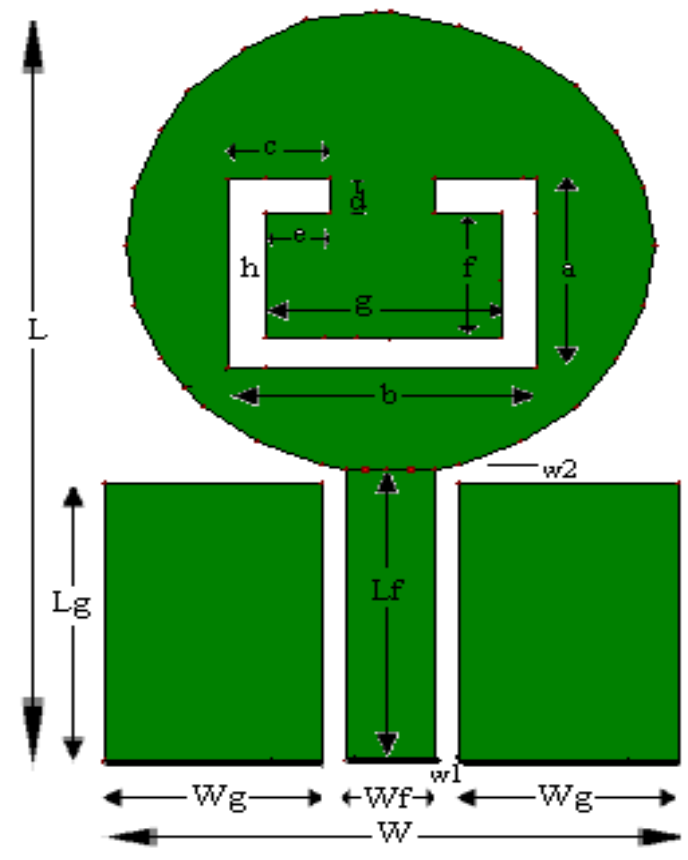

Figure 1: Diagram of proposed antenna 


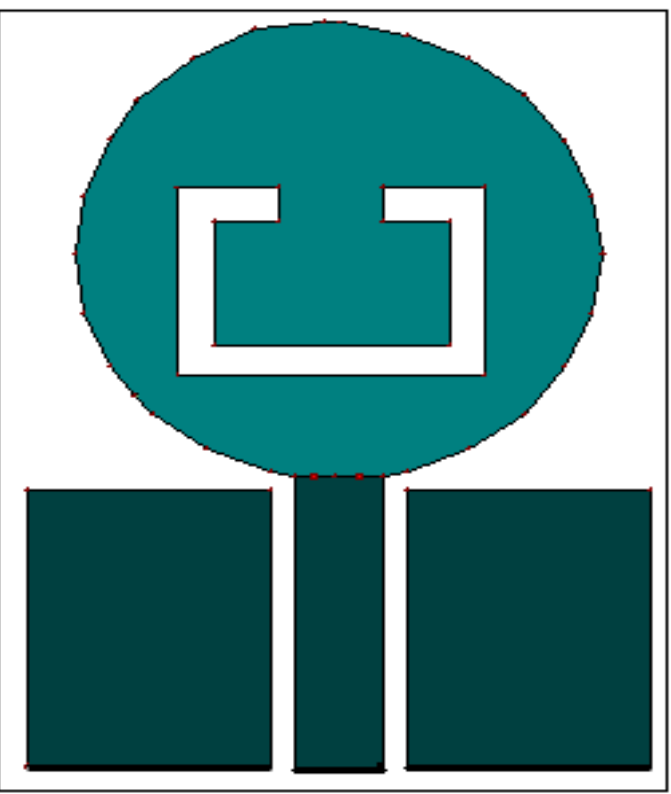

Figure 2 : Prototype of fabricated antenna

Table 1: Different parameters of antenna

\begin{tabular}{|c|c|}
\hline Parameters & Values(mm) \\
\hline L & 33 \\
\hline W & 24 \\
\hline Lg & 12.4 \\
\hline Wg & 9.4 \\
\hline Lf & 13 \\
\hline Wf & 3.5 \\
\hline w 1 & 0.87 \\
\hline w 2 & 0.63 \\
\hline R & 10 \\
\hline a & 8.4 \\
\hline b & 11.8 \\
\hline c & 3.9 \\
\hline d & 1.5 \\
\hline e & 2.5 \\
\hline f & 5.56 \\
\hline g & 9.0 \\
\hline h & 1.4 \\
\hline & \\
\hline
\end{tabular}

\section{SIMULATED RESULTS AND DISCUSSIONS}

The simulated return losses and other parameter results are obtained. The return losses of the proposed antenna are shown in Fig. 3. The result shows that the antenna exhibits impedance bandwidth from $4.2 \mathrm{GHz}$ to $10.5 \mathrm{GHz}$ centered at 8.9 GHz. The peak value of return loss is $-33 \mathrm{db}$. This implies that it covers UWB band from $4.5 \mathrm{GHz}$ to $10.5 \mathrm{GHz}$.

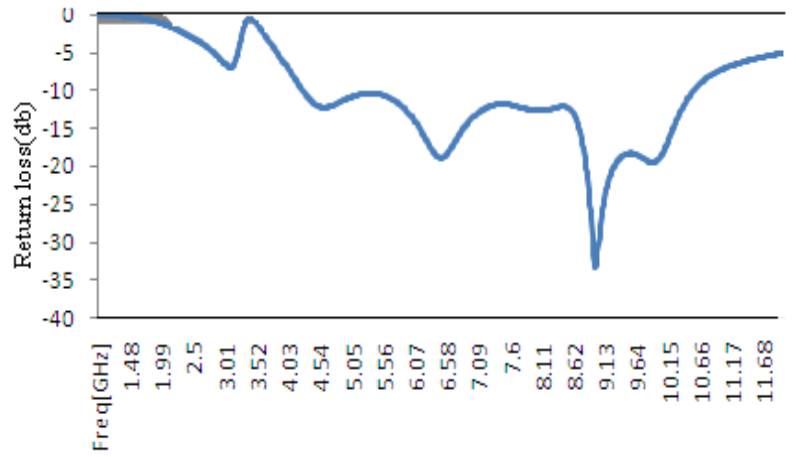

Figure 3: Result of proposed antenna

Fig. 3 shows the parametric study of the proposed antenna. It shows the comparison graph of return losses when there was no slots in patch, there was slots in the patch. When no slot was embedded in the patch, impedance bandwidth increased from 3.8 to 11.7 but peak of return losses was decreased to 28 $\mathrm{db}$. After adding slots, peak value is increased to higher value i.e $33 \mathrm{db}$ and the optimum results are obtained.

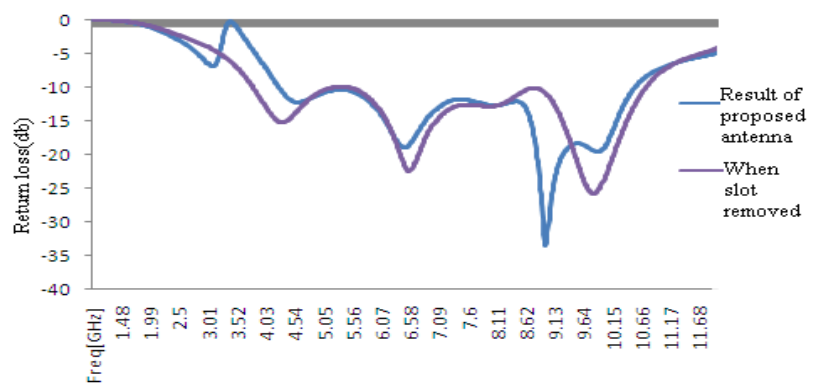

Figure 4: Comparison of result of proposed antenna with and without slot

Fig 5 also shows the affect of various parameters on the result of antenna. It shows the comparison graph when ground width is increased, when slot width is decreased and when ground length is increased. When length of ground was increased, peak value of return losses was decreased to $28 \mathrm{db}$ and bandwidth was centered at $8.7 \mathrm{GHz}$ and when width of slot was reduced, peak value of return loss of antenna was decreased to $-19 \mathrm{db}$.

Fig 6 shows the current distribution of proposed antenna. Current distribution is changed by changing the length and dimensions of patch. 


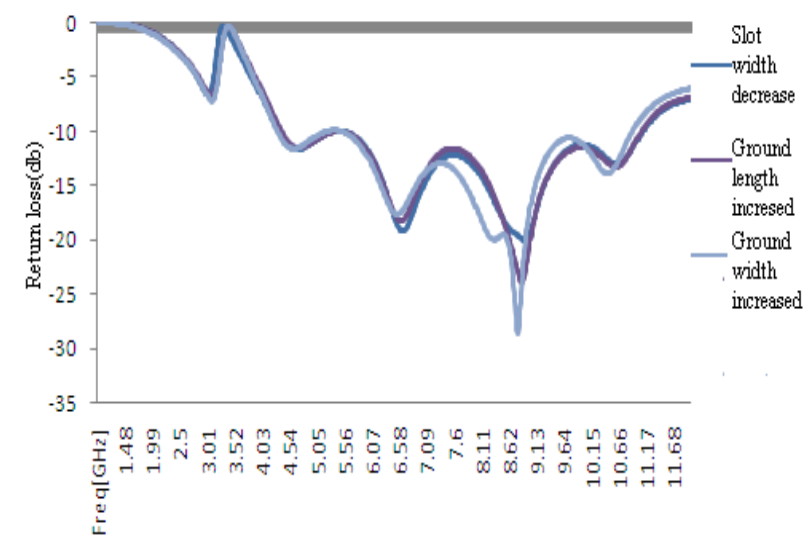

Figure 5: Comparison of return losses of (a) Antenna when ground width increased (b) Antenna when slot width decreased (c) Antenna when ground length increased

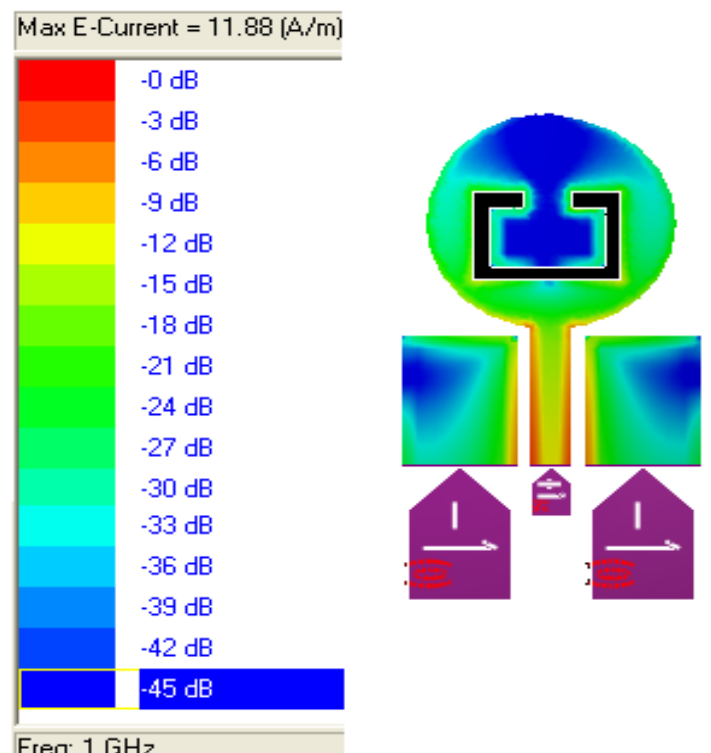

Fig 6: Current distribution of proposed antenna

The maximum current is 11.8 amperes. Figure 7 shows simulated 2D radiation patterns for elevation and azimuth plane near at resonant frequencies $8.9 \mathrm{GHz}$. Radiation pattern presents the graphical representation of radiation properties of antenna as a function of space co-ordinates. Fig. 7(a) shows elevation pattern gain display and fig 7(b) shows azimuth pattern gain display at $8.9 \mathrm{GHz}$.

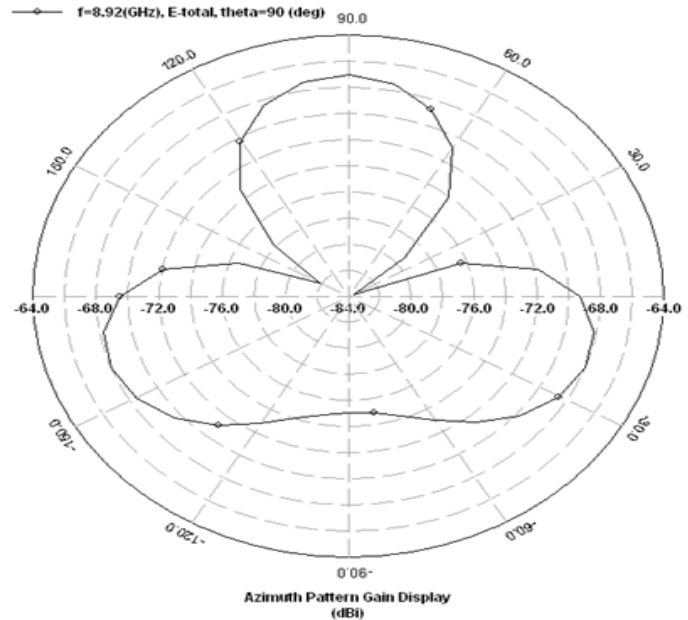

Fig 7(a) Elevation pattern gain display at $8.9 \mathrm{GHz}$

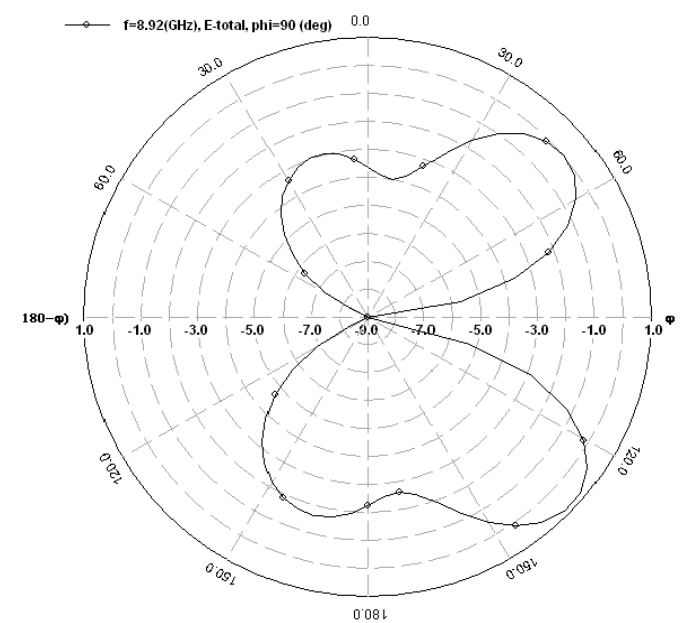

Fig 7(b): Azimuth pattern gain display at $8.9 \mathrm{GHz}$

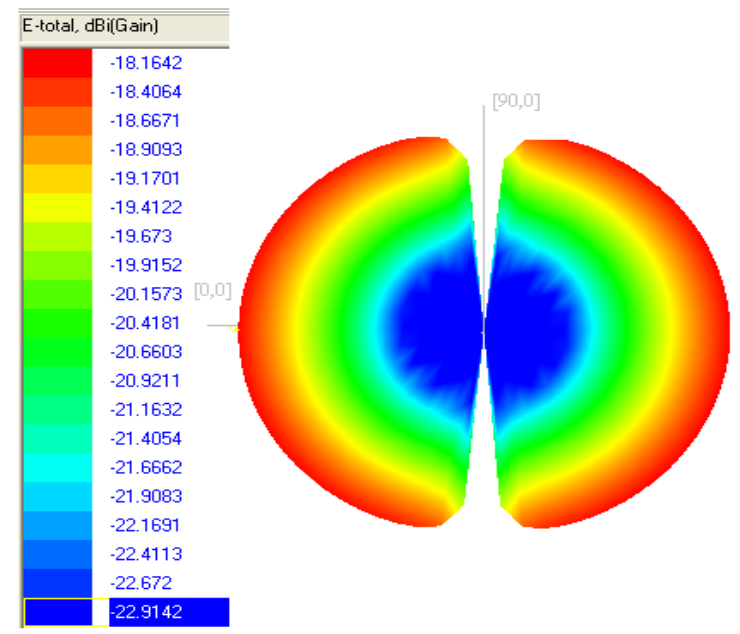

Fig 8: 3D Radiation Pattern of Antenna

Fig. 9 represents the gain versus frequency curve of the proposed UWB antenna. The gain versus frequency curve shows that it has maximum gain at the desired resonant frequency. For the working band 4.2 to $10.5 \mathrm{GHz}$, the maximum gain is $7 \mathrm{dbi}$. As a result, the gain of proposed 
antenna satisfies the requirement of ultra-wide band applications.

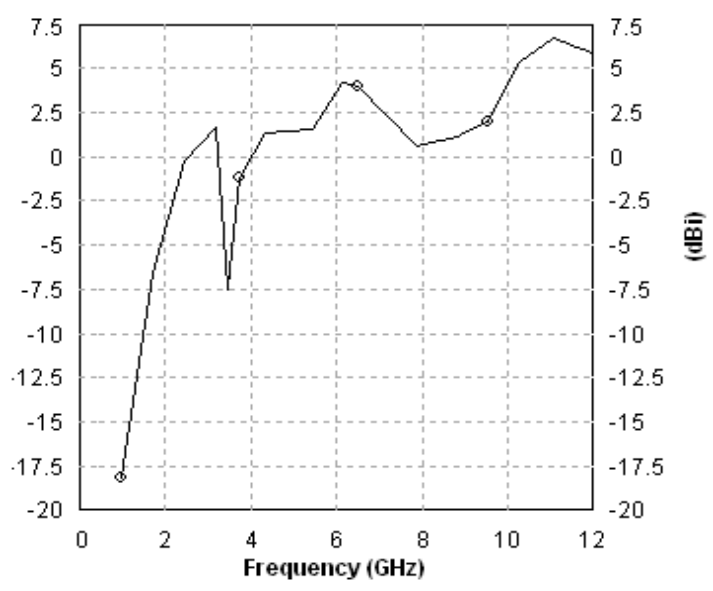

Figure 9: Gain of proposed Antenna

Figure 10 shows the efficiency of proposed antenna. The antenna has maximum efficiency of $91 \%$.

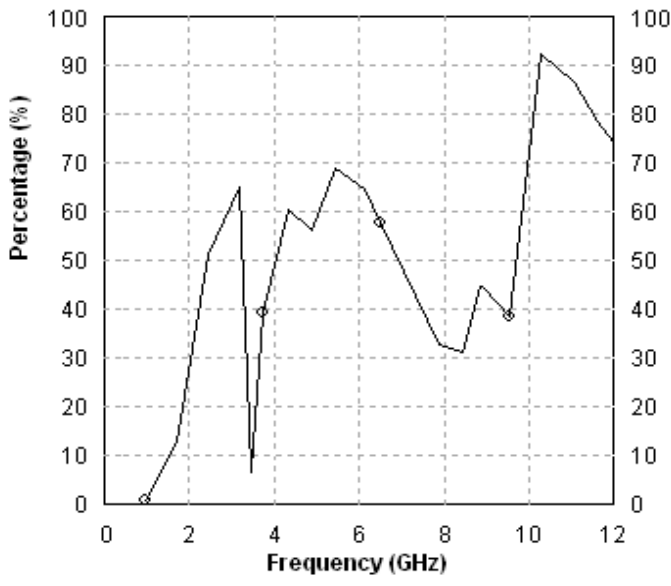

Figure 10: Efficiency of proposed antenna

\section{CONCLUSION}

A circular antenna suitable for UWB applications is proposed. Effects of varying dimensions of key structure parameters on the antenna and various parameters like length of ground, dimensions of slot and their performance are also studied. Moreover, the proposed antenna has several advantages, such as small size, excellent radiation patterns, and higher gains and good efficiency. These characteristics are very attractive for some wireless communication systems for a variety of applications. This antenna covers frequency band from 4.2 to $10.5 \mathrm{GHz}$

\section{REFERENCES}

[1] E.S.Angelopoulos, "Circular and elliptical CPW fed slot and microstrip-fed antenna for UWB Application" IEEE Trans. Antennas Propagation vol. 5, 2006, pp. 294-297.

[2] C.Marchais, G.Leray "Strip line slot Antenna for UWB communication" IEEE Trans. Antennas Propagation vol. 5, 2006, pp. 319-322.

[3] Qing-Xin Chu, "A compact UWB antenna a with 3.4/5.5 $\mathrm{GHz}$ dual band Notch characteristics" IEEE Trans. Antennas Propagation vol. 56, 2008, pp. 3637-3644.

[4] X.Qing, Z.N.chen "CWB-fed UWB monopole -like slot antenna”, IET Antenna Propagation Feb. 2008, pp 889899.

[5] Z.Li, C-X, Zhang, "Design CPW-fed Aperture antenna for UWB Application", Progress in Electromagnetic Research Vol.2, 2008.

[6] G.M.Yang,R.H.Jin,G.B.Xiao, "UWB Antenna with Multi Resonator Split-Ring Loops" IEEE Trans.Antennas Propagation vol. 57, 2009, pp256-260.

[7] Shun-Yun Lin, "A Novel Compact Slot Antenna for Ultra Wideband Communication," IEEE International Symposium. PP.5123-5126.June 2007.

[8] T.A Denidni and M.A.Habib. "Broandband printed CPW- fed circular slot antenna," Electronics Letters, Vol.42, Feb 2006.

[9] S.W.Qu, C.Ruan and B.Z.Wang, "Bandwidth enhancement of wide slot antenna fed by CPW and microstrip line," IEEE antennas and Wireless Propagation Letters. Vol.5. PP15-17, 2006. 